\title{
Tax Effects in Canadian Equity Option Markets
}

\author{
Moshe Arye Milevsky \\ York University, Canada \\ Eliezer Z. Prisman \\ York University, Canada
}

The Canadian Income Tax Act induces individual investors to close their short equity option positions at the end of the year and, if necessary, reopen them at the beginning of next year. This article analyzes the conditions under which it is optimal to close or leave open a short option position over the tax year boundary. The analysis shows that the latter decision depends on transaction costs, the investor's marginal tax rate, the interest rates, the initial and end-of-the-year option prices, as well as whether the option position is naked or covered. The article also examines the impact of tax regulations in Canada on the pricing of naked vs. covered call options and American vs. European options (JEL G13, H21, K34).

Key words: derivative securities, equity options, open interest, tax arbitrage.

\section{Introduction}

Canadian tax authorities consider the short-sale (writing) of an exchange traded equity option as a taxable transaction. Under this policy, a Canadian investor ${ }^{1}$ - as opposed to a trader or a dealer- who

\footnotetext{
* The authors would like to thank Narat Charupat, David Goldreich, Eliakim Katz, Michael Knoll, Peter Maclaurin, Glenn May, John Rumsey, Tom Salisbury, the participants at the Northern Finance Association's 1996 annual meeting, the editor, and two anonymous MFJ reviewers for helpful comments. This article was supported by a grant from the York University Research Authority and the Social Sciences and Humanities Research Council of Canada.
}

1. A Canadian investor is simply an individual who pays capital gains-as opposed to ordinary income —on all investment transactions.

(Multinational Finance Journal, 1997, vol. 1, no. 2, pp. 101-122)

(C) by Multinational Finance Society, a nonprofit corporation. All rights reserved. DOI: $10.17578 / 1-2-2$ 
writes a call or put option must declare the premium received as a capital gain in the year in which the option is written. Subsequently, at the time the position is liquidated, the investor must report any funds paid to settle the transaction as a capital loss. If the option is exercised early, the original premium is added to the exercise proceeds to reduce the adjusted cost base of the underlying security.

This regulation creates a situation where it is not optimal for the Canadian investors to carry an open short equity option position to the next calendar ( $\operatorname{tax}$ ) year, regardless of whether there is an unrealized profit or loss from the option transaction. Therefore, the regulation induces Canadian investors to close short positions at the end of the year and, if necessary, reopen them at the beginning of next year.

The popular investment press has been encouraging investors to apply the aforementioned tax-saving strategy. ${ }^{2}$ Nevertheless, as shown in this article, the optimality of the strategy depends, among other things, on the embedded transaction costs, the interest rates, the investor's marginal tax rate, and whether the short option position is naked or covered. ${ }^{3}$ In addition, the strategy carries the implicit risk of adverse price movements prior to the reestablishment of the original position. This article analyzes the conditions under which it is optimal for a Canadian investor to close or leave open a short option position over the tax year boundary in the presence of personal taxes and transaction costs.

The analysis, also, shows that the equilibrium price of a covered call option may be different from that of a naked call option due to differential tax treatment of sellers and buyers of options. As a result, it is always optimal to have the position exercised against the writer as opposed to closing out in the secondary market. Moreover, the tax regulation makes American-type equity options more attractive for the writers than European-type equity options. Thus, causing a situation where, other things being equal, American-type equity options could trade at a lower price than European-type options.

The behavior of Canadian investors around the end of the year is examined using open interest data from the Toronto Stock Exchange

2. See Cohen (1994) for details.

3. Naked options are options for which the buyer or seller has no underlying security position. A writer of a naked call option, therefore, does not own a long position in the stock on which the call has been written. Similarly, the writer of a naked put option does not have a short position in the stock in which the put has been written. 
(TSE). ${ }^{4}$ The results show that there is a notable decrease in open interest toward the end of the year and a notable increase in open interest at the beginning of the year. This phenomenon is consistent with the hypothesis that Canadian investors will either close or refrain from opening short option positions toward the end of the year.

Unlike in Canada, the U.S. Internal Revenue Code taxes equity option premia at the time the position is terminated. In this respect, there is no tax incentive for U.S. investors to close short positions prior to the end of the year. An empirical examination of the open interest on the Chicago Board Options Exchange (CBOE) does not reveal the seasonal pattern present in the Canadian market. This finding further supports the end-of-the-year behavior of Canadian investors.

The article is organized as follows. Section II presents a brief literature review pertaining to the effect of tax regulation on the option markets. Section III provides a summary of options tax code in Canada and numerical examples. Section IV analyzes the conditions under which it is optimal to close or leave open a short option position prior over the tax year boundary and examines the impact of tax regulation in Canada on the pricing of naked vs. covered calls and American vs. European options. Section V presents empirical findings on the behavior of investors in the US and Canada regarding short equity option positions around the end of the tax year. The article ends with a summary and concluding remarks in section VI.

\section{Literature Review}

Scholes (1976) employs quantitative reasoning similar to that used in Black and Scholes (1973) to derive the equilibrium price model for call options in a world with taxes. ${ }^{5}$ Scholes' model implies that, other things being equal, higher taxes would result in higher hedge ratios-because the tax authorities by allowing losses to be tax deductible, share in the risk of the option position - and lower option prices. Moreover, Scholes recognizes that due to the multitude of tax brackets in the marketplace, it is impossible to determine the exact price at which an option will sell.

4. Open interest refers to the total number of contracts in an option market that are still open; i.e., they have not been exercised, closed out, or expired.

5. Note that the resulting differential equation for the call option price with taxes is similar to that with dividends. In the latter case, however, the dividend yield term is replaced with the product of risk free rate and marginal tax rate on capital gains. 
Scholes (1976), however, does not address the issue of liquidating a position in order to avoid taxes. In fact, continuing Scholes line of thought, other things being equal, higher capital gains taxes are likely to induce more investors to liquidate their short option positions before the end of the year.

Constantinides and Scholes (1980) explore the possibility of taxarbitrage in exchange option markets due to the fact that a losing option position by an individual on one side of the transaction can be closed without a contemporaneous gain recognition by the individual on the other side of the transaction. This is because a contract buyer is not matched with a particular contract seller; but rather, the clearinghouse is the counterpart to both transactions. Specifically, the authors focus on the ability to defer paying capital gains by building a portfolio of equity options that establishes a capital loss in one tax year with an equal but opposite capital gain in the next tax year. Repeating this pyramiding scheme, one could defer capital gains taxes until death. Note, however, that the stringent wash sales and offsetting position rules applied by the US tax authorities on such transactions deter investors from using this option strategy. ${ }^{6}$ Such a strategy is probably one of the reasons why the Canadian authorities tax the option premium in the year in which it is received.

Viswanath (1989), and Cornell and French (1983) show that the tax treatment of futures $v s$. the underlying security provide incentives to hold one instrument over the other, despite the fact that on a pretax basis they are identical. Empirical evidence from futures markets confirm the latter finding.

Finally, Sternberg (1994), and Knoll (1994) show that the well known put-call parity relationship breaks down on an after-tax basis due to the treatment of the interest income and capital gains. These authors also focus on the implications of personal taxes on the options trading.

\section{Tax Environment for Options}

The Canadian Income Tax Act does differentiate between traders and investors for tax purposes. According to the Act, "a trader is an individual whose whole course of conduct indicates the carrying on of

6. Wash sale refers to the purchase and sale of substantially identical securities, including options, either simultaneously or within a short period of time (30 days). Loses arising from wash sales do not qualify as tax loses. Under offsetting position rules, losses in one year can be offset by gains in other years. 
a business or adventure or concern in the nature of trade." Factors considered when trying to ascertain the course of conduct include, but are not limited to, the frequency of transaction turnover, knowledge of securities markets, time spent studying the securities markets, sophistication of trading methodology, financing procedures and other operating similarities with professional dealers. That is, an individual exhibiting similar characteristics to those of a professional trader will be classified as such for tax purposes. Otherwise, the individual will be classified as an investor. Note that, unlike in the US, the class of traders in Canada includes full-time doctors, lawyers, and engineers, provided that they meet the above criteria.

This article focuses on tax regulations pertaining to Canadian investors. As a general rule, Canadian investors have all proceeds from the disposition of financial assets, net of allowable expenses, taxed as capital gains or losses at the time of disposition. ${ }^{7}$ Currently, only 75 percent of capital gains are taxed. Therefore, an investor in the 35 percent federal marginal tax bracket, will pay $\$ 100 \times .75 \times .35=\$ 26.25$ for every $\$ 100$ in capital gains.

The Canadian tax authorities view the writing (granting) of an exchange-traded equity option by an investor the same as the sale of an asset with a zero adjusted cost base. ${ }^{8}$ As a result, the writer of the option incures a capital gains tax liability equal to the premium received from the writing of the option. The net tax liability is a function of the writer's tax bracket and proportion of net taxable capital gains. For options expiring out of the money (worthlessly), the writer assumes no further tax liability. Moreover, the purchase of identical options by the writer for the purpose of closing a short position is deductible expenditure. Thus, it is treated as a capital loss.

When a call option is exercised, the writer of the option is forced to sell the underlying security to the holder of the option at a price equal to the option's strike price. Thus, the writer's revenue is equal to the sum of the strike price and the original premium received from the writing of the call option. For put options, the writer is forced to buy the underlying security from the holder of the put option at a price equal to the strike price. Thus, the purchase cost for the securities is equal to the strike price minus the premium received from writing the put option.

7. In the context of this article, negative capital gains imply capital loses. Similarly, negative profits imply loses.

8. Canadian Income Tax Act, Section 49, no. 1. 
If the writing and subsequent exercise of an option took place in different tax years, the writer could amend the tax return and remove the option premium from the capital gains proceeds of the year in which the options was written. ${ }^{9}$ In this case, the writer is entitled to a tax refund equal to the amount of tax paid on the option premium plus interest. Obviously, if the writing and exercise of an option took place during the same tax year there would be no need to amend the tax return.

The tax treatment of option premia in Canada for investors buying (holding) options is different from that of investors selling (writing) options. Investors buying options must wait until the options are expired or exercised before determining the tax-status of the premia paid. When expired, the option premia paid are treated as capital losses. When exercised, the premia are incorporated into the revenue or costbasis of the underlying stock. Specifically, for call options the premia are added to the cost basis of the acquired stocks and for put options the premia are subtracted from the sale proceeds of stocks.

In the US, the writing of an exchange-traded equity option induces no immediate tax liability to the investor. The writer of an option is required to carry the premium received in a deferred account until the obligation from the option expires or terminates. Termination occurs when the short position is closed or the option is exercised. At this point, the investor determines the tax consequences to the transaction. ${ }^{10}$

In the US, when an option expires worthlessly, the premium received by the writer is treated as a short-term capital gain, regardless of the amount of time that has elapsed since the original writing of the option. If the writer decides to close the position with the purchase of an identical option, the premium paid for the new option will be deducted from the original premium received to determine the net gain or loss that will be taxed as short-term capital gain or loss. If a call option is exercised and the writer is forced to sell the underlying stock to the holder of the call option at the strike price, then the writer must report the original option premium received as part of the sale proceeds of the stock. The corresponding capital gain from the disposition of the stock is treated as a long or short-term capital gain depending on the holding period of the stock. ${ }^{11}$

9. Canadian Income Tax Act, Sec. 49, no. 4. Interpretation Bulletin No. IT-479R § 29.

10. US Revenue Ruling 58-234, 1958-1 Cumulative Bulletin page 283.

11. The holding period depends on whether the option was a qualified covered call. 
TABLE 1. Canadian Income Tax Regulations for Investors Writing Equity Options

\begin{tabular}{|c|c|c|}
\hline & $\begin{array}{l}\text { Tax liability for the } \\
\text { year in which the } \\
\text { option is written }\end{array}$ & $\begin{array}{l}\text { Tax liability for subsequent } \\
\text { years in which the position } \\
\text { is still open }\end{array}$ \\
\hline \multicolumn{3}{|l|}{$\begin{array}{l}\text { A. Position is terminated } \\
\text { during initial tax year }\end{array}$} \\
\hline Expired worthless & $\begin{array}{l}\text { Capital gain on entire } \\
\text { premium }\end{array}$ & $\mathrm{n} / \mathrm{a}$ \\
\hline Closed with a gain & Capital gain on net & $\mathrm{n} / \mathrm{a}$ \\
\hline Closed with a loss & Capital loss on net & \\
\hline Covered Call exercised & $\begin{array}{l}\text { Exercise price plus } \\
\text { premium considered } \\
\text { sale proceeds for stock }\end{array}$ & $\mathrm{n} / \mathrm{a}$ \\
\hline Naked Call exercised & $\begin{array}{l}\text { Capital gain/loss on } \\
\text { net } P \& L\end{array}$ & $\mathrm{n} / \mathrm{a}$ \\
\hline Put Exercised & $\begin{array}{l}\text { Exercise price minus } \\
\text { premium is the purchase } \\
\text { basis for stock holding }\end{array}$ & $\mathrm{n} / \mathrm{a}$ \\
\hline \multicolumn{3}{|l|}{$\begin{array}{l}\text { B. Position is open over the } \\
\text { initial tax-year boundary } \\
\text { and terminated in the } \\
\text { subsequent tax-year }\end{array}$} \\
\hline Expired worthless & $\begin{array}{l}\text { Capital gain on entire } \\
\text { premium }\end{array}$ & $\mathrm{n} / \mathrm{a}$ \\
\hline Closed with a gain & $\begin{array}{l}\text { Capital gain on entire } \\
\text { premium }\end{array}$ & Capital loss \\
\hline Closed with a loss & $\begin{array}{l}\text { Capital gain on entire } \\
\text { premium }\end{array}$ & Capital loss \\
\hline Covered Call exercised & $\begin{array}{l}\text { (Temporary) Capital } \\
\text { gain on entire premium }\end{array}$ & $\begin{array}{l}\text { Amend - Exercise price plus } \\
\text { premium considered sale } \\
\text { proceeds for stock }\end{array}$ \\
\hline Naked Call exercised & $\begin{array}{l}\text { Capital gain on entire } \\
\text { premium }\end{array}$ & $\begin{array}{l}\text { Capital gain/loss on net } \\
\text { P\&L }\end{array}$ \\
\hline Put exercised & $\begin{array}{l}\text { (Temporary) Capital } \\
\text { gain on entire premium }\end{array}$ & $\begin{array}{l}\text { Amend - Exercise price } \\
\text { minus premium is the } \\
\text { purchase basis for stock } \\
\text { holding }\end{array}$ \\
\hline
\end{tabular}

For puts, the writer is forced to purchase the stock at the strike price and must deduct the premium received in computing the adjusted cost basis 
of the stock. The holding period for the stock starts on the exercise date of the put option. Table 1, provides a summary of the equity option tax treatment of Canadian investors.

\section{A. Numerical Examples}

On July 1, 1996, the market price of the XYZ stock is $\$ 60$. Moreover, the price of $100 \mathrm{XYZ}$ call options with a strike price of $\$ 60$ maturing in 18 months (henceforth, called XYZ c60's) is $\$ 1,500 .{ }^{12}$ Investors $A$ and $\mathbf{B}$ write (sell) $100 \mathrm{XYZ}$ c60's for a premium of $\$ 1,500$. Investor A keeps a short naked call option position. Investor B keeps a short covered call option position. That is, investor $\mathbf{B}$ uses the proceeds from the sale of call options and a cash outlay of $\$ 4,500$ to buy $100 \mathrm{XYZ}$ stocks. According to the Canadian tax code, a naked call option position cannot be covered by establishing a long position in the underlying stock at a later point in time. ${ }^{13}$

For simplicity, assume that (a) all investors are in the 50 percent marginal tax bracket, (b) regardless of profit or loss, investors liquidate their stock position at expiration, (c) borrowing, lending and tax refund interest rates are the same, (d) the twelve-month interest rate is 10 percent, and (e) the eighteen-month interest rate is 15 percent.

On December 31, 1996, the price for an XYZ stock falls to $\$ 40$ and for $100 \mathrm{XYZ}$ c60's falls to $\$ 800$. Investors who keep their short call position open over the tax year boundary are subject to a tax liability of $\$ 750(=\$ 1,500 \times .5)$ for the initial premium received. For reference purposes, these investors are denoted by $\mathbf{A 1}$ and B1. Investors who close their short position by purchasing $100 \mathrm{XYZ}$ c60's at $\$ 800$ are subject to a tax liability of $\$ 350(=[\$ 1,500-\$ 800] \times .5)$. Immediately after the tax year is over, these investors can sell $100 \mathrm{XYZ}$ c60's at $\$ 800$ and reestablish their short call position. Because the position will be closed at a profit, there is no problem with wash sale rules. The latter investors are denoted by $\mathbf{A} \mathbf{2}$ and $\mathbf{B 2}$.

On December 31, 1997 (expiration), the price of the XYZ stock is $\$ 80$. Thus, the $100 \mathrm{XYZ}$ c60's are worth $\$ 2,000$. Taking into account time value of money, the after-tax economic gain for investor $\mathbf{A 1}$, with

12. Note that the $\$ 1,500$ for the option is a pure time premium because the strike price and market price of the underlying stock are equal.

13. The tax treatment for covered calls applies only when the stock is acquired prior to the short sale of the option; see Adamson (1992). 
the open naked call option position over the tax year boundary, is

$$
\begin{gathered}
\overbrace{(\$ 1,500 \times 1.15-\$ 2,000)}^{\text {pre-tax gain }}-\overbrace{(\$ 0-\$ 2,000) \times .5}^{\text {current tax }} \\
-\overbrace{(\$ 1,500 \times .5 \times 1.1)}^{\text {future value of tax }}=-\$ 325 .
\end{gathered}
$$

The after-tax economic gain for investor $\mathbf{A 2}$, with the closed naked call option position over the tax year boundary, is

$$
\begin{gathered}
\overbrace{(1,500 \times 1.15-\$ 2,000)}^{\text {pre-tax gain }}-\overbrace{(\$ 800-\$ 2,000) \times .5}^{\text {current tax }} \\
-\overbrace{(\$ 1,500-\$ 800) \times .5 \times 1.1}^{\text {future value of tax }}=-\$ 285 .
\end{gathered}
$$

Thus, a greater after-tax loss is suffered from keeping the position open over the tax year boundary rather than closing the position. This is a direct consequence of the fact that the tax code does not take into account time value of money. Thus, investors benefit by shifting portion of their tax liability to a subsequent year. Specifically, the $\$ 40$ difference is the interest earned on $\$ 400$ tax deferred to the second year.

The after-tax economic gain for investor B1, with the open covered call option position over the tax year boundary, is

$$
\begin{gathered}
\overbrace{(\$ 6,000-\$ 4,500 \times 1.15)}^{\text {pre-tax gain }}-\overbrace{(\$ 7,500-\$ 6,000) \times .5}^{\text {current tax }} \\
+\overbrace{(\$ 1500 \times .5 \times 1.1)}^{\text {tax refund }}-\overbrace{(\$ 1,500 \times .5 \times 1.1)}^{\text {future value of tax paid }}=\$ 75 .
\end{gathered}
$$

The after-tax economic gain for investor B2, with the closed-covered call option position over the tax year boundary, is

$$
\overbrace{(\$ 6,000-\$ 4,500 \times 1.15)}^{\text {pre tax gain }}-\overbrace{(\$ 6,800-\$ 6,000) \times .5}^{\text {pre tax gain }}
$$




$$
-\overbrace{(\$ 1,500-\$ 800) \times .5 \times 1.1}^{\text {future value of tax paid }}=\$ 40 .
$$

Indeed, in the covered call case, it is preferable to leave the position open. As shown in section IV, when the call option is in the money, it is optimal to close a naked call position, but not a covered call position.

\section{Model and Optimality Conditions}

This section investigates the optimality conditions for the decision to close or leave open a short equity option position over the tax year boundary - closed the last day of first year and reopened the first day of the next year-for naked call, covered call and naked put option positions. The decision criteria are obtained by comparing the expected future value of the stock option portfolio under both modes of behavior.

Model Assumptions. The option is written at the beginning of the first tax year, denoted by $t=0$. All taxes incurred during the first year are payable on the last day of the same year, denoted by $t=1$. The option expires on the last day of the second tax year $(t=2)$. All tax liabilities incurred during the second year are payable at $t=2$. The interest rate for period $t=0$ to $t=2$ is equal to $R^{a}$ and for period $t=1$ to $t=2$ is equal to $R^{b}$. In the case of amended tax returns, the authorities return the tax paid on the original option premia plus interest, based on an interest rate of $R^{x}$, which is always less than $R^{b}$. All decisions take place at $t=1$, at which point all interest rates are deterministic. Wash sale rules for paper losses are fully enforced. ${ }^{14}$ Regardless of profit or loss, investors liquidate any stock position at time $t=2$. Capital loses at time $t=2$ are deducted from other capital gains.

\section{A. Naked Call Option Position}

A short naked call option position left open over the first year tax boundary creates a tax liability at $t=1$ equal to $c_{0} \tau$, where $c_{0}$ is the price of the call option at $t=0$ and $\tau$ is the investor's marginal tax rate. The future value of this tax liability at expiration $(t=2)$ is $c_{0} \tau\left(1+R^{b}\right)$. At expiration, the writer is forced to pay the holder of the call option an

14. That is, a losing position that is closed and subsequently re-opened, is treated as a wash sale. The tax-basis remains the same and the loss cannot be deducted. 
amount equal to $\max \left(S_{2}-K, 0\right)$, where $S_{2}$ is the market price of the underlying security at expiration and $K$ is the option strike price. The writer's tax refund for the payments is equal to $\max \left(S_{2}-K, 0\right) \tau$. Note that when the call option does not finish in the money $\left(S_{2}<K\right)$, the writer pays nothing and receives no tax refund. The after-tax economic value at expiration for an open short naked call option position is

$$
\begin{gathered}
c_{0}\left(1+R^{a}\right)-\max \left(S_{2}-K, 0\right) \\
+\max \left(S_{2}-K, 0\right) \tau-c_{0} \tau\left(1+R^{b}\right) .
\end{gathered}
$$

On the other hand, the after-tax economic value for a closed naked call option position over the tax year boundary is

$$
\begin{gathered}
c_{0}\left(1+R^{a}\right)-\max \left(S_{2}-K, 0\right) \\
-\left[\min \left(c_{0}, c_{1}\right)-\max \left(S_{2}-K, 0\right)\right] \tau \\
-\max \left(c_{0}-c_{1}, 0\right) \tau\left(1+R^{b}\right)-T C\left(1+R^{b}\right),
\end{gathered}
$$

where $c_{1}$ is the call option price at $t=1$ and $T C$ is a dollar-valued transaction cost for closing and re-opening the position around the tax year end. The above equation assumes that the position is reopened at exactly the same price, $c_{1}$, for which it was closed. When $c_{1}<c_{0}$, the position is closed with a profit and there is an immediate tax liability of $\left(c_{0}-c_{1}\right) \tau$. But, when $c_{1}>c_{0}$, the position is closed with a loss. The latter loss cannot be deducted when the position is subsequently reopened because it constitutes a wash sale. In the event of a wash sale, the tax basis of the new position will be the initial call option price of $c_{0}$. Therefore, the future value of the tax liability in equation 2 is equal to $\max \left(c_{0}-c_{1}, 0\right) \tau\left(1+R^{b}\right)$.

The benefit function for closing the short naked call option position, given by the difference of (2) and (1), is

$$
\min \left(c_{0}, c_{1}\right) R^{b} \tau-T C\left(1+R^{b}\right)
$$

A positive value for the benefit function implies that the investor should 
close the naked call position at the end of the year and a negative value implies that the investor should leave the position open. Note that the latter decision depends on transaction cost, the interest rate $R^{b}$, the marginal tax rate $\tau$, as well as the option prices at $t=0$ and $t=1$.

\section{B. Covered Call Option Position}

The initial cost of a covered call short option position $(t=0)$ is equal to $-\left(S_{0}-c_{0}\right)$. The payoff of the call option at expiration $(t=2)$ is equal to. The future value of the pretax profit from the portfolio is $\min \left(K, S_{2}\right)-\left(S_{0}\right.$ $\left.-c_{0}\right)\left(1+R^{a}\right)$.

A short call option position left open over the first year tax boundary generates a tax liability equal to $c_{0} \tau$. The future value of the latter tax liability is $-c_{0} \tau\left(1+R^{b}\right)$. Note that when the call option finishes in the money, the tax authorities refund the tax on the initial option premium with a suitable interest. The after-tax economic value of a short open covered call option position is

$$
\begin{gathered}
\min \left(K, S_{2}\right)-\left(S_{0}-c_{0}\right)\left(1+R^{a}\right) \\
-\left[\min \left(K, S_{2}\right)+c_{0} 1_{\left\{K<S_{2}\right\}}-S_{0}\right] \tau \\
+c_{0} \tau\left(1+R^{x}\right) 1_{\left\{K<S_{2}\right\}}-c_{0} \tau\left(1+R^{b}\right),
\end{gathered}
$$

where $1_{\left\{K<S_{2}\right\}}$ is an indicator function that takes the value of one when the option expires in the money and the value of zero otherwise.

The after-tax economic value for a closed covered call option position over the tax year boundary is

$$
\begin{gathered}
\min \left(K, S_{2}\right)-\left(S_{0}-c_{0}\right)\left(1+R^{a}\right) \\
-\left[\min \left(K, S_{2}\right)+\min \left(c_{0}, c_{1}\right)-S_{0}\right] \tau \\
-\max \left(c_{0}-c_{1}\right) \tau\left(1+R^{b}\right)-T C\left(1+R^{b}\right)
\end{gathered}
$$

The benefit function for closing the covered call option position over 
the tax year boundary, given by (5) minus (4), is

$$
\min \left(c_{0}, c_{1}\right) \tau R^{b}-c_{0} \tau R^{x} 1_{\left\{K<S_{2}\right\}}-T C\left(1+R^{b}\right)
$$

When the above function is positive, or when

$$
\min \left(1, \frac{c_{1}}{c_{0}}\right) \frac{R^{b}}{R^{x}}-\frac{T C\left(1+R^{b}\right)}{c_{0} \tau R^{x}}>1_{\left\{K<S_{2}\right\}},
$$

it is worthwhile to close and vice versa.

Intuitively, if the transaction costs from closing the position were large relative to the change in option price, the position should be left open. On the other hand, if the transaction costs were small, and when $c_{1}>c_{0}$, the position should be closed. Note that the left-hand side of (7) is deterministic at time $t=1$, but the right-hand side is stochastic and depends on the distributional properties of log-returns of the underlying security.

Proposition 1. A risk-neutral Canadian investor will close a covered short equity option position at the end of the tax year, if

$$
\min \left(1, \frac{c_{1}}{c_{0}}\right) \frac{R^{b}}{R^{x}}-\frac{T C\left(1+R^{b}\right)}{c_{0} \tau R^{x}}>E\left(1_{\left\{K<S_{2}\right\}}\right) .
$$

In the Black-Scholes (1973) setting, the optimality condition for closing a short position is given by

$$
\min \left(1, \frac{c_{1}}{c_{0}}\right) \frac{R^{b}}{R^{x}}-\frac{T C\left(1+R^{b}\right)}{c_{0} \tau R^{x}}>N\left(d_{2}^{\mu}\right),
$$

where

$$
\begin{gathered}
d_{2}^{\mu}=\frac{\ln \left(S_{1} / K\right)+\left(\mu-\frac{1}{2} \sigma^{2}\right)(T-t)}{\sigma \sqrt{T-t}}, \\
N(z)=\int_{-\infty}^{z} \frac{1}{\sqrt{2 \pi}} \exp \left(-\frac{1}{2} z^{2}\right) d z
\end{gathered}
$$

$\left(\mu, \sigma^{2}\right)$ are the mean and variance of the log-returns of the underlying 
security, $T-t$ is the time left to expiration of the option, and $N\left(d_{2}^{\mu}\right)$ is the probability that the option will be in the money at maturity.

\section{Naked Put Option Position}

This subsection presents the optimality conditions for closing a short naked put option position over the tax year boundary. It can be easily shown that the after-tax economic value for an open short naked put option position over the tax year boundary is

$$
\begin{gathered}
p_{0}\left(1+R^{a}\right)-\max \left(K-S_{2}, 0\right) \\
-\left[p_{0} 1_{\left\{S_{2}<K\right\}}-\max \left(K-S_{2}, 0\right)\right] \tau \\
+p_{0} \tau\left(1+R^{x}\right) 1_{\left\{S_{2}<K\right\}}-p_{0} \tau\left(1+R^{b}\right),
\end{gathered}
$$

where $p_{0}$ is the price of the put at $t=0$. The after-tax economic value for a closed naked put option position over the tax year boundary is

$$
\begin{gathered}
p_{0}\left(1+R^{a}\right)-\max \left(K-S_{2}, 0\right) \\
-\left[\min \left(p_{0}, p_{1}\right)-\max \left(K-S_{2}, 0\right)\right] \tau \\
-\max \left(p_{0}-p_{1}, 0\right) \tau\left(1+R^{b}\right)-T C\left(1+R^{b}\right) .
\end{gathered}
$$

The benefit function for closing the short naked put position over the tax year boundary, given by (12) minus (11), is

$$
\min \left(p_{0}, p_{1}\right) \tau R^{b}-p_{0} \tau R^{x} 1_{\left\{S_{2}<K\right\}}-T C\left(1+R^{b}\right)
$$

Proposition 2. A risk-neutral investor will close a short naked put option position at the end of the tax year if

$$
\min \left(1, \frac{p_{1}}{p_{0}}\right) \frac{R^{b}}{R^{x}}-\frac{T C\left(1+R^{b}\right)}{p_{0} \tau R^{x}}>E\left(1_{\left\{S_{2}<K\right\}}\right)
$$


In the Black-Scholes (1973) setting, the optimality conditions for closing the position over the tax year boundary is

$$
\min \left(1, \frac{p_{1}}{p_{0}}\right) \frac{R^{b}}{R^{x}}-\frac{T C\left(1+R^{b}\right)}{p_{0} \tau R^{x}}>N\left(-d_{2}^{\mu}\right),
$$

where $N\left(-d_{2}^{\mu}\right)$ is obtained from equations 9 and 10 and gives the probability that the put option will be in the money at maturity.

\section{Naked Call vs. Covered Call Option Position}

The after-tax economic values for an open short naked call option position, given by (1), is

$$
\begin{gathered}
c_{0}\left(1+R^{a}\right)-\max \left(S_{2}-K, 0\right) \\
+\max \left(S_{2}-K, 0\right) \tau-c_{0} \tau\left(1+R^{b}\right),
\end{gathered}
$$

for an open short-covered call option position, given by (4), is

$$
\begin{gathered}
\min \left(K, S_{2}\right)-\left(S_{0}-c_{0}\right)\left(1+R^{a}\right) \\
-\left[\min \left(K, S_{2}\right)+c_{0} 1_{\left\{K<S_{2}\right\}}-S_{0}\right] \tau \\
+c_{0} \tau\left(1+R^{x}\right) 1_{\left\{K<S_{2}\right\}}-c_{0} \tau\left(1+R^{b}\right),
\end{gathered}
$$

and for long position in the stock is

$$
S_{2}-S_{0}\left(1+R^{a}\right)-\left(S_{2}-S_{0}\right) \tau
$$

Financial economic theory assumes that the value of a portfolio is equal to the sum of its respective components. This additivity property is a characteristic of most valuation models. Note, however, that the sum of (1) and (15) is not equal to (4). In fact, subtracting (1) and (15) 
from (4) yields the stochastic term ${ }^{15}$

$$
R^{x} c_{0} \tau 1_{\left\{K<S_{2}\right\}}
$$

The above result implies that on an after-tax basis, an open covered call option position is more valuable than an open naked call option plus a long position in the stock; although on a pretax basis the two are identical. This brings to mind the question of blatant tax-arbitrage opportunities and specifically whether it is possible to sell (1) and (15) and buy (4) so as to obtain the spread of $R^{x} c_{0} \tau 1_{\left\{K<S_{2}\right\}}$. In practice, this would involve buying a call, given by (16), and short selling a stock, and then acquiring a covered call option portfolio. However, this will not work because buying a call will not result in an after-tax payoff that is opposite in sign to that of equation 1 , because of the aforementioned asymmetric tax treatment of buyers and sellers. The holder of a long call can wait until the position is closed, exercised or expires before determining tax consequences. Therefore, the nonlinear tax-arbitrage opportunity disappears as a result of the non-symmetric tax treatment.

\section{E. American vs. European Options}

An important by-product of the above discussion is that a bundled short covered call is more valuable than a short call separated from a long stock. Thus, a covered call option that is about to expire in the money should not be closed-out in the options market. By letting an option be exercised, the investor gets a more preferential tax treatment than by covering the position and selling the stock in the market, even though the pretax cash flows are exactly the same. This is because, the exercise will trigger the tax-return amendment which will result in a premium refund. This refund will be lost if the option is closed-out. Based on equation 16, the covered option writer prefers the option to expire in the money, than slightly out of the money. For example, when the market price of the stock, an instant prior to expiration, is $S_{2-\varepsilon}<K$, then

$$
K-S_{2-\varepsilon}=\delta<R^{x} c_{0} \tau,
$$

it would be preferable to have the option end up in-the-money.

15. With repetitive application of the identity $\mathrm{A}-\max (\mathrm{A}-\mathrm{B}, 0)=\min (\mathrm{A}, \mathrm{B})$. 
As it is evident from equations 16 and 17, if the tax authorities did not refund the original premium with interest $\left(R^{x}=0\right)$, then the tax treatment of a covered call would be identical to the tax treatment of naked call plus a long position in stock, thus restoring linearity and additivity to the market. However, on the other hand, if $R^{x}=0$, then from equation lit is always optimal to close the short position at year end. In either case a distortion will exist.

Under certain conditions a Canadian investor may prefer to sell (write) an American (early exercise) call option instead of an otherwise identical European call option, given that the prices are equal. This is contrary to the currently accepted principle that in the absence of dividends, a writer would be indifferent between the writing of an American or a European type call option. The latter principle holds because in options markets without rigidities an American option is worth more "alive" than dead (exercised). Thus, investors (buyers) will hold such an option until maturity. On the contrary, this article shows that the writer (seller) may prefer to have the option exercised prior to its maturity. In an efficient capital market the latter preference will be reflected in the price of the option. As a result, an American call option will sell for less than an otherwise identical European call option. It is worth noting, however, that the latter proposition is not testable because all exchange traded equity options in Canada are American style.

\section{Statistical Evidence}

If indeed it is optimal for many Canadian investors to close their short equity option positions prior to the end of the tax year, then logic dictates that there should be evidence of this behavior in the marketplace. We postulate that the aggregate open interest in the options market provides a good proxy for the above behavior of Canadian investors. Specifically, as the tax year comes to an end, the open interest in the options market should display a noticeable decrease as previously open positions are closed in anticipation of the tax consequences. Also, investors will defer from writing options until the beginning of next tax year in order to save on the time value of money emanating from any tax liability. For example, an investor (especially in a high tax bracket) contemplating the short sale of an option in the month of December is much better off postponing such an activity until January. Consequently, at the beginning of the tax year there will be a 
significant increase in open interest stemming from those investors who either closed or deferred their short option positions toward the end of the previous tax year.

Figure should no exceed 3" x 4.25"

It should be in a camera ready form.

Figure 1.-Average Monthly Percentage Change in Open Interest on the Toronto Stock Exchange: 1981-1996.

Figure 1 provides an illustration of the average monthly change in open interest from 1981 to 1996. It appears from the figure that, on average, open interest tends to decrease toward the end of the tax year and then increase at the beginning of the year. In particular, the months of November and December exhibit the largest decrease in open interest, while the months of January and March exhibit the largest increase in open interest.

The first two columns of table 2 give the means and standard deviations of the monthly percentage changes in open interest during the period 1981-96. The last column gives the $p$-values for testing the null hypothesis that the average monthly percentage change in open interest is zero. Note that the null hypothesis is rejected at the five percent level of significance for the months of January, March, and November, and at the 6.6 percent level of significance for the month of December. Moreover, the mean values for the months of November and December are negative and for the months of January and February are positive. 
The last two rows of the table, provide the mean values for the change in open interest in the first three and the last three months of the tax year. The null hypothesis that the two means are equal is rejected at the five percent level of significance $(p-$ value $=.02)$.

TABLE 2. Monthly Open Interest on the TSE, 1981-1996

\begin{tabular}{lccc}
\hline Month & Mean Change (\%) & Standard Deviation & $p$-Value \\
\hline January & 5.22 & 8.43 & .043 \\
February & .84 & 5.86 & .600 \\
March & 5.67 & 8.70 & .029 \\
April & -.87 & 5.83 & .586 \\
May & .76 & 10.88 & .798 \\
June & 1.72 & 9.31 & .501 \\
July & -2.77 & 7.16 & .171 \\
August & -.71 & 7.82 & .741 \\
September & 1.87 & 10.16 & .502 \\
October & -.90 & 10.41 & .753 \\
November & -3.95 & 6.13 & .031 \\
December & -3.43 & 6.38 & .066 \\
& & & \\
Test for Equality of Means & & & .02 \\
First three months of the year & 3.91 & 8.07 & \\
Last three months of the year & -2.76 & & \\
\hline
\end{tabular}

Note: $\mathrm{H}_{0}$ : Average monthly percentage change at year end is equal to zero. $\mathrm{H}_{1}$ : Average monthly change at year end is not equal to zero

These results are consistent with the proposition that Canadian investors close or refrain from opening short equity option positions toward the end of the tax year. Also, the results are consistent with the assertion that, other things being equal, Canadian investors prefer to open their short equity option positions at the beginning of the tax year in order to postpone paying tax on the premium.

The seasonal changes in open interest may be attributed to microstructural factors, such as the natural cycle for option expiration. However, there is no a priori reason to believe that options are more likely to expire in December than they are in January. In fact, options are more likely to expire in January. This should not impact open interest, because when one series terminates another one starts.

As a means of comparison with the US, data on open interest on the Chicago Board Options Exchange (CBOE) are collected. 
Figure should no exceed 3" x 4.25"

It should be in a camera ready form.

FIgURE 2.-Average Monthly Change in Open Interest on the Chicago Board Options Exchange: 1978-1996.

Figure 2 provides an illustration of the percentage change in open interest for equity options traded on the $\mathrm{CBOE}$ and cleared through the Option Clearing Corporation. Contrary to the TSE, open interest on the CBOE does not appear to decline prior to the end of the tax year. Similar statistical tests show that there are no significant differences in open interest during the first three and the last tree months of the year. The null hypothesis of equality of the means could not be rejected at any reasonable level of significance. The latter findings depict that the decrease in open interest at the end of the year and the increase in open interest at the beginning of the year is a Canadian phenomenon. ${ }^{16}$

16. The open interest on the CBOE does exhibit a high degree of monthly variability. This variability may be attributed to the expiration of certain option series (triple witching day) and other micro-structural reasons. In the year 1985, the CBOE changed the system of expiration cycles. Up to that year, all equity options were on a strict quarterly system in which options on any particular stock were traded with four monthly maturities during the year. After 1985, the current and next month were added to each options series. Thus, it is quite possible that the CBOE data prior to the year 1985 are not indicative of any tax-induced phenomenon. In fact, Exxon, IBM and Kodak are among the (large volume) options that have January maturity cycles and hence may have influenced the pre-1985 results. 


\section{Conclusion}

The Canadian tax code stipulates that the writing (granting) of an exchange traded equity option constitutes a taxable transaction. Under the code, a Canadian investor writing an option must declare the premium received as a capital gain in the year in which the option is written. When the option is exercised-provided that the exercise takes place in a different year than the writing of the option-the investor amends the tax return for the year in which the option was written and receives a tax refund plus interest. The tax code provides incentives to investors to close short option positions at the end of the tax year, regardless of whether there is an unrealized profit or loss on the option transaction. If deemed appropriate, the investors may reopen these positions at the beginning of next year. Empirical evidence based on open interest data from the TSE and CBOE are in line with the aforementioned behavior of Canadian investors around the tax year end.

This article shows that optimality of the strategy to close a short call option position over the tax year boundary depends on transaction costs, interest rates, marginal tax rates, the initial and end-of-the-year option prices, as well as, whether the option position is naked or covered. Moreover, the strategy carries the implicit risk of adverse price movement prior to the reestablishment of the original position.

In addition, the article shows that the equilibrium price of a covered call option may be different from that of a naked call option due to the differential tax treatment between buyers and sellers of options. The latter tax asymmetry breaks down the principle of cash-flow additivity present in valuation models. Finally, the article shows that, other things being equal, Canadian investors prefer selling American style (early exercise) options than European style options. This creates a situation where American equity options may possibly trade for less than similar European equity options.

This article concludes that the Canadian Income Tax Act causes distortions in the Canadian option markets that impose unnecessary deadweight costs on economic activity. Moreover, the tax asymmetry that exists between buyers and sellers of options results in violations of option pricing principles present in well functioning markets. Canada is the only industrialized country in which written (short) equity options are treated as a zero cost basis investment but at the same time are not marked-to-market at the end of the tax year. It is necessary that the tax authorities implement one of the following two policy changes: (1) mark to market the short equity option at the end of the tax year, or (2) adopt 
a wait and see approach like in the US. Either of these changes will eliminate the economic incentives to close and reopen short option positions and will restore the pricing principles present in efficient option markets.

\section{References}

Adamson, P. 1992. Personal tax planning: Portfolio securities transactions. Canadian Tax Journal 40, no. 3: 736-762.

Arnason S. and Jagannathan, R. 1994. Evaluating executive stock options using the binomial option pricing model. Working Paper. Minnesota: University of Minnesota.

Black F. and Scholes M. S. 1973. The pricing of options and corporate liabilities. The Journal of Political Economy 81: 637-653.

Cohen, B. 1994. A tax strategy for options players. The Financial Post (December 22): 24.

Constantinides, G. M. and Ingersoll J. E. 1984. Optimal bond trading with personal taxes. Journal of Financial Economics 13, no. 3: 299-335.

Constantinides, G. M. and Scholes M. S. 1980. Optimal liquidation of assets in the presence of personal taxes: Implications for asset pricing. Journal of Finance 35, no. 2: 439-449.

Cornell B. and French, K. R. 1983. Taxes and the pricing of stock index futures. Journal of Finance 38, no. 3: 675-694.

Hogg R. and Mallin M. 1994. Preparing Your Income Tax Returns. Nort York, Ontario: CCH Canadian Limited.

Knoll, M. S. 1994. Put-call parity and the law. Working paper. University of Southern California Law Center.

Kramer, A. S. 1991. Financial Products: Taxation, Regulation and Design. New York: John Wiley.

Scholes, M. S. 1976. Taxes and the pricing of options. Journal of Finance 31, no. 2: 319-332.

Seyhun, H. N. and Skinner, D. J. 1994. How do taxes affect investors stock market realizations? Evidence from tax-return panel data. Journal of Business 67, no. 2: 231-262.

Sternberg, J. S. 1994. A reexamination of put-call parity on index futures. Journal of Futures Markets 14, no. 1: 79-101.

Viswanath, P. V. 1989. Taxes and the futures-forward price difference in the 91-day T-bill market. Journal of Money Credit and Banking 21, no. 2:190-205. 